Área Temática: Educação Visual, Linguagens Visuais e Arte

\title{
DOSSIÊ
}

\section{POLIFILO E O SONHO DE ALDO MANUZIO}

\section{Ubirajara Alencar Rodrigues}

\section{RESUMO}

Estudo sobre a tipologia gráfica e ilustrações da obra Hypnerotomachia Poliphili, de Aldo Manuzio, através da Arte da Memória e da rede de imagens que a envolve.

PALAVRAS-CHAVE

Arte da memória; Tipografia; Artes visuais

\section{POLIFILO AND THE DREAM OF ALDO MANUZIO}

\section{ABSTRACT}

Study on the graphical typology and illustrations of the work Hypnerotomachia Poliphili, of Aldo Manuzio, through the Art of Memory and the network of images that involves it.

\section{KEYWORDS}

Art of memory; Printing; Visual arts 


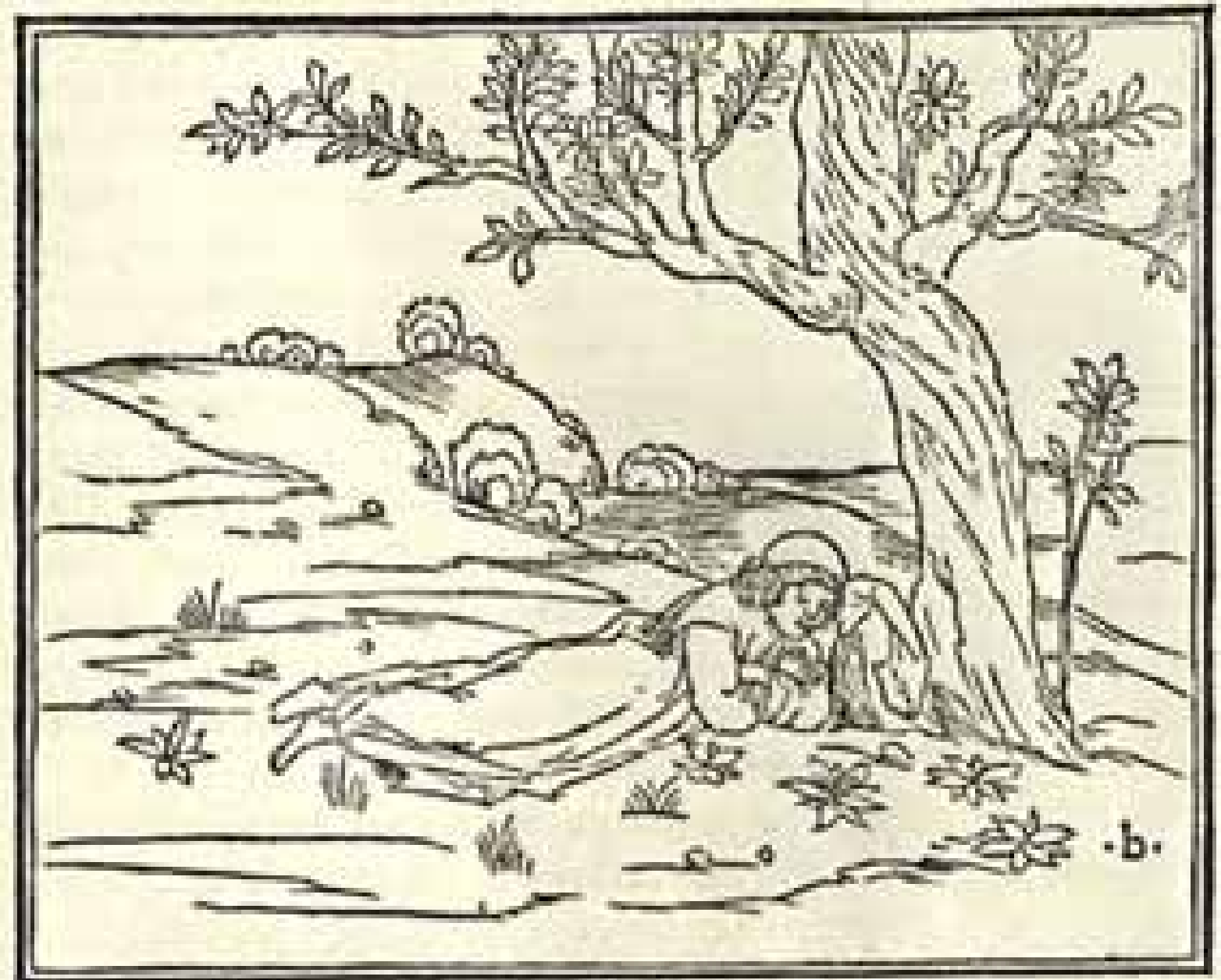




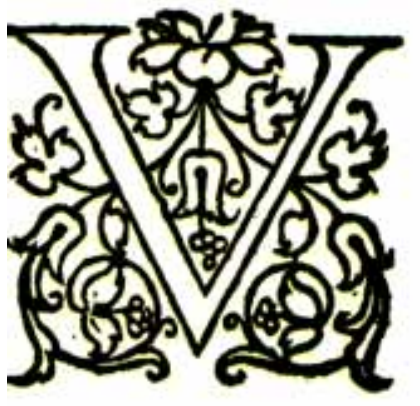

EMOS NO LIVRO QUE LEMOS, HOJ E, A MEMÓRIA VISUAL DO livro manuscrito e de seus sucessores impressos produzidos entre os anos de 1455 e 1500: os incunábulos. Aqui, porém, fixarei o olhar com mais vagar no Hypnerotomachia Poliphili1, do frade dominicano Francesco Colonna, publicado por Aldo Manuzio em Veneza, em 1499. Os nossos melhores livros contemporâneos tentam apresentar clareza na diagramação e buscam a perfeição na relação entre texto e imagens, qualidades banais nessa obra.

Restringindo-me ao século $\mathrm{XV}$ e respeitando as particularidades dos diversos tipos de impressão feitas por outros editores nesse período - que são belíssimas - lembro que elas imitavam os manuscritos à exaustão antes de Manuzio; a inserção de iluminuras após a impressão mecânica é um exemplo. Naquele momento de mudança, os livros impressos por Aldo Manuzio foram exóticos por simplificar, abdicando da pretensão de igualar os livros manuscritos. Ainda assim, ele manteve o uso de capitulares no início dos capítulos, uma herança de textos da Antigüidade que reverberou intensamente tanto nos livros manuscritos quanto nos impressos. A clareza que Manuzio apresentou naquela diagramação, hoje é comum, já que em 500 anos a arte da memória se incumbiu de registrá-la nos olhares dos leitores e dos editores. Ainda pensando nos leitores, os tipos que utilizamos atualmente, como o que tece essas palavras, derivam daqueles que Manuzio e boa parte dos outros editores italianos utilizavam nos seus livros.

Sigo Yates que disse que "...na época anterior à imprensa o adestramento da memória era de extraordinária importância."2, mas penso que o livro tornou-se mais um personagem visual desse adestramento que atualmente é mais intenso. Aos nossos olhos são expostas imagens - impostas - que se tornarão memórias visuais, pela excessiva exposição a que somos submetidos. Não é mais necessária a intercessão dos mediadores que ensinavam a mnemotécnica, como na época de Cícero.

Nesse texto que apresento a seguir, tento mostrar que Polifilo ${ }^{3}$ está imerso na arte da memória e aparece quando lemos nossos livros, confirmando que as imagens que Manuzio e Griffo ${ }^{4}$ gravaram são perenes. 
Quando nos sentamos diante de um microcomputador e abrimos programas como o Word, geralmente o fazemos para escrever um texto contínuo: uma carta, um trabalho para a faculdade/ escola, um ensaio, um artigo, etc. Quando pensamos em escrever algo, hoje, automaticamente nos dirigimos à mesa onde está esse equipamento que, num primeiro momento, substitui a máquina de escrever, transformada numa peça de museu para alguns. Somos contemporâneos dos dois equipamentos e a associação com essa palavra - museu - pode causar desconforto a algumas pessoas por ser ligada a coisas velhas. À palavra museu e a outras quaisquer me refiro pensando no que trazem consigo, dependendo naturalmente de quem as escreve e de quem as lê; dependendo de outras palavras e dos espaços com os quais estejam convivendo. Algumas palavras, como as de Jorge Luis Borges, por exemplo, não cabem nas páginas dos livros - transbordam - e se não as contivermos no livro com cuidado serão derramadas na mesa, na poltrona, no chão, nas nossas roupas, na nossa pele... Como se palavras, como as de Borges, pudessem ser contidas.

Nos programas de edição de texto temos imagens - memórias visuais que nos remetem aos primeiros livros impressos e, especificamente àqueles impressos por Aldo Manuzio (Aldus Manutius), que desenvolveu suas atividades em Veneza, entre 1495 e 1515, aproximadamente.

Nesses programas de edição de texto, ao digitarmos as letras estamos criando laços entre urdume e trama e formando um tecido para ser lido. Eventualmente guiamos o cursor pelo monitor até o ícone que representa as letras itálicas para destacar uma palavra ou um grupo delas em relação ao conjunto. A letra itálica é "a letra inclinada, geralmente à direita, usada como meio de realce; aldino, grifo, letra grífica, letra itálica [O tipo itálico foi desenhado para o impressor Aldus Manutius, em 1501, a partir da letra chanceleresca cursiva, por Francesco Griffo da Bologna (donde o sinônimo grifo), e, posteriormente, aperfeiçoado por Ludovico degli Arrighi]"5. Hoje, geralmente usamos esse recurso com outros propósitos, mas foi concebido inicialmente para aproveitar melhor o espaço da página dos livros de bolso que exigiam a acomodação do máximo de letras nas páginas. Era, então, um personagem presente em toda a página. 
Quando configuramos a página de um texto no microcomputador, definimos características herdadas dos primeiros incunábulos e dos livros de Manuzio. O formato da página, as dimensões das margens que definem a disposição da mancha do texto, o tipo e o tamanho das letras, os parágrafos, o alinhamento do texto.

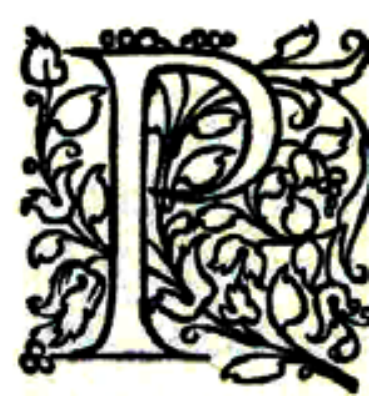

ENSAR NO TIPO É PENSAR EM QUEM O CRIOU E SUA memória. Pensar na tinta que gravou o desenho do tipo é pensar no negro de fumo 6 e suas matérias primas e na memória de quem as produziu. Pensar no papel que recebe a tinta nos incunábulos ${ }^{7}$ é pensar nos trapos e na memória de quem teceu o tecido desses últimos, manuseou a pasta que geraria o papel, a secou, até que nele esses trapos se transformassem. Para J ameson "memórias são, acima de tudo, recordações dos sentidos, pois são os sentidos que lembram, e não a 'pessoa' ou a identidade pessoal."8

Quando J orge Luis Borges falou das escritas do deus, juntei suas palavras às de Frances Yates para pensar a Arte da Memória. Para ele a escrita está nas manchas do jaguar:

"Dediquei longos anos a aprender a ordem e a configuração das manchas. Cada cega jornada me concedia um instante de luz, e assim pude fixar na mente as negras formas que riscavam a pelagem amarela. Algumas incluíam pontos; outras formavam raias transversais na face interior das pernas; outras anulares, se repetiam. Talvez fosse um mesmo som ou uma mesma palavra, muitas tinham bordas vermelhas." 9

E nas montanhas, nos rios, impérios ou astros:

"Uma montanha..., ou um rio ou o império ou a confirmação dos astros. Mas no curso dos séculos as montanhas se aplainam e o caminho de um rio costuma desviar-se e os impérios conhecem mutações e estragos e a figura dos astros varia. No firmamento há uma dança..."10 Outra linguagem, hermética, que se transforma todos os dias, e exige constante observação para ser decifrada quando de novo a buscarmos.

E também nos espaços entre as palavras... 


\section{Área Temática: Educação Visual, Linguagens Visuais e Arte}

"o número de símbolos ortográficos é vinte e cinco"11 - 22 letras, a vírgula, o ponto e o espaço, símbolo fundamental que guarda escondidas outras memórias, imaginações...

Frances Yates escreveu:

"Poucos sabem que os gregos, que inventaram muitas artes, inventaram também uma arte da memória que, como outras artes, passou a Roma, de onde derivou a tradição européia. Essa arte ensina a memorizar valendo-se de uma técnica mediante a qual se imprimem na memória lugares e imagens."12

Os textos desses autores os trazem para que conversemos e conversemos num labirinto infinito. Numa cela, como Polifilo.

A cela, a selva, o livro e o sonho são lugares por onde as almas viajam. Criam seus Alephs.

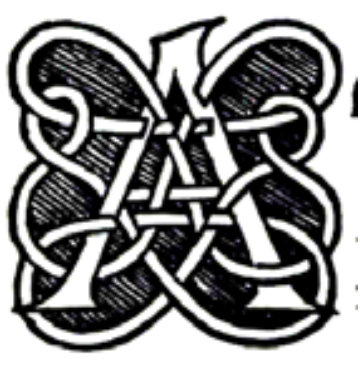

LEPH! FRANCESCO COLONNA, FRADE DOMINICANO pertencente ao convento veneziano de San Giovanni e San Paolo, que viveu aproximadamente entre 1433 e 1527, foi o provável autor do Hypnerotomachia Poliphili (Batalha de Amor em Sonho de Polifilo), livro publicado em 1499 por Aldo Manuzio, em Veneza. Foi identificado bem depois da edição do livro, pela observação do acróstico formado pela letra inicial (capitular) da primeira palavra de cada um dos 38 capítulos do Hypnerotomachia Poliphili: "POLIAM FRATER FRANCISCUS COLUMNA PERAMAVIT" (Frade Francesco Colonna amou muitíssimo Polia).

Colonna vestiu-se de Polifilo e através das palavras e imagens fez um teatro do mundo, uma enciclopédia que, porém, pressupõe dos leitores uma iniciação ao conhecimento de palavras, mitos e livros; uma vasta memória cultural de imagens e um inesgotável interesse pelo mistério e pelas entrelinhas deste; não basta ler e ver, é necessário descobrir, para reconstruir.

“Os mais antigos e sábios escritores sempre tiveram o costume de esconder os segredos de Deus em seus escritos sob os obscuros véus, para que só fossem entendidos por aqueles que (como diz Cristo) têm ouvidos para ouvir, isto é, por aqueles eleitos por Deus para entender seus santíssimos mistérios. E Melisso diz que os olhos das almas vulgares não podem suportar os raios da divindade."13

Talvez Colonna tenha consultado um Aleph ao escrevê-lo.

“... um Aleph é um dos pontos do espaço que contém todos os pontos."14 
Com a ajuda de Giorgio Agamben ${ }^{15}$ destaco um detalhe interessante que pode guiar-nos ao início do entendimento do Hypnerotomachia Poliphili: a tradução das palavras que compõem esse título. Como já foi citado acima, em grego essas palavras significam "Batalha de amor em sonho de Polifilo".

“Polia (poliòs, polià) significa simplesmente 'a grisalha, a velha' e Polifilo não é outro que 'aquele que ama a velha'."16

Agamben também diz que a velha pode ser a Antigüidade, o que pode ser confirmado pelas imagens que acompanham todo o texto do livro. O autor deve ter viajado muito num momento em que a arqueologia, ainda amadora, praticada por colecionadores, era esboçada. O artigo de Agamben: "Per una lettura del Polifilo" trata, principalmente, dos conflitos entre duas línguas: o latim e o vulgar; que se tornaram uma terceira - a polifilesca - no Hypnerotomachia Poliphili. A leitura dessa obra, porém, não pode ser feita sem que leiamos as imagens - ou tentemos -, que compõem um conjunto hermético junto ou como letras de um alfabeto ou hieróglifos egípcios.

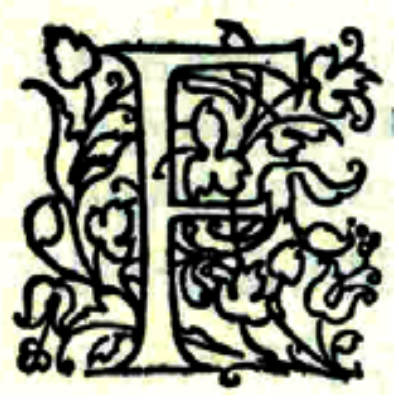

RANCESCO PETRARCA (1304-1374), POETA, e ALDO MANUZIO (1450-1515), editor, não se conheceram pessoalmente. Entretanto, a obra literária de Petrarca e os livros impressos pelo tipógrafo Manuzio são perenes. Humanistas e italianos, ambos tiveram o livro como guia e destino nos seus cotidianos profissionais.

Petrarca foi preparado para ser advogado nas Universidades de Montpellier e Bologna; Manuzio era um professor, preceptor de nobres - os príncipes de Carpi; profissões que, teoricamente, garantiriam a eles algum status, respeito e uma vida digna. Abriram mão disso. Numa carta, Petrarca escreveu:

"Chamam-me um desertor e me consideram como alguém que, iniciado nos ares sagrados, depois de tê-los violado ou transgredido, acabou por divulgar os mistérios de Ceres Eleusínia ${ }^{17}$. Pois que eu, meu amigo, destinado pelo meu pai àqueles estudos quando contava 12 anos, me transferi primeiramente a Montpellier e depois a Bologna, consumi sete anos inteiros e aprendi os rudimentos tanto quanto me consentiam a idade e o engenho. Se me arrependo do tempo transcorrido, não saberia dizer; no entanto, enquanto me agrada ter experiências em geral, desagrada-me ter perdido grande parte da vida, que é breve; e disso me arrependo para sempre."18 
Manuzio publicou em 1501 o "Le cose volgare", e em 1514, "Le Rime", de Petrarca. Em 1499, a obra desse poeta reverberaria juntamente com a de Dante, Boccaccio, Virgílio, e de outros escritores, no "Hypnerotomachia Poliphili", de Francesco Colonna, publicado por Manuzio.

“...os mais ilustres códices literários a disposição de Colonna, aqueles de Dante e Petrarca, implicam a morte da amada como premissa essencial ao seu funcionamento...Polia, viva na dedicatória, morta nos epitáfios que a precedem e a seguem nos dois extremos do Hypnerotomachia Poliphili, tem a mesma função de Beatriz no Vita Nuova... e na Commedia de Dante e de Laura no Canzoniere e nos Triumphi de Petrarca, ou seja, testemunha de uma... virada existencial do autor, que comporta profundas mudanças também dos meios formais da escrita." 19

"A hora que tem início o sonho é o átimo no qual surge o esplendor auroral e coincide, na ficção literária, com a duração do tempo onírico no qual se desenrola a trama do romance inteiro. ... aqui o uso da RINGKOMPOSITION (elo de composição) que abre e fecha a narração, resulta um artifício fundamental da literatura clássica e medieval (basta citar, entre os mais célebres casos, aquele do Enéias virgiliano... que inicia e conclui com um sonho as suas peregrinações, ou então aquele do ciceroniano Somnium Scipionis, 10 e 29, onde a viagem transcendente é compreendida entre o adormecer e o despertar do narrador, estrutura que de resto reaparecerá pontual no ROMAN DE LA ROSE20. . . como também em Boccaccio...)"21

Nos anos de Petrarca, no século XIV, o livro, então manuscrito por copistas profissionais - operários da escrita -, era a fonte de conhecimento. Calígrafo, Petrarca manuscrevia pequenos livros com sua escrita Carolina e parece ter influenciado Manuzio na escolha dos tipos de letras a empregar em seus livros e no uso de pequenos livros de mão. Nesse ínterim, entre a morte de Petrarca e o início das atividades de editor de Manuzio, porém, a escrita Humanística, minúscula, herdeira da escrita carolíngia e conseqüentemente da Carolina, já recebera impulso do notário florentino Poggio Bracciolini (13801459). 


\section{DOSSIÊ \\ Área Temática: Educação Visual, Linguagens Visuais e Arte}

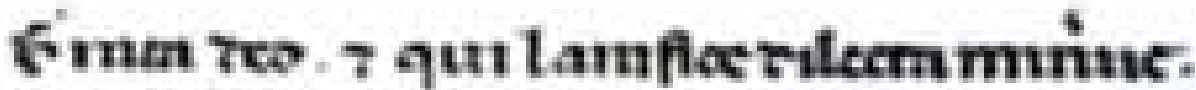

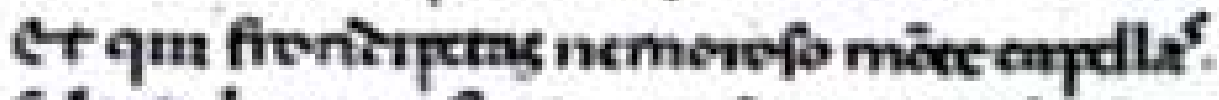

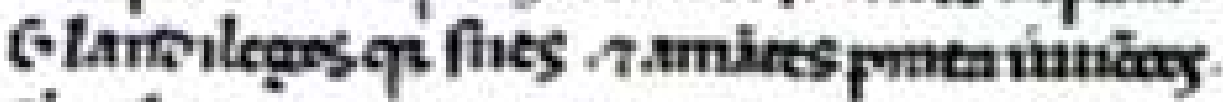
T'turbu unens - unap dis i gurgute taniam

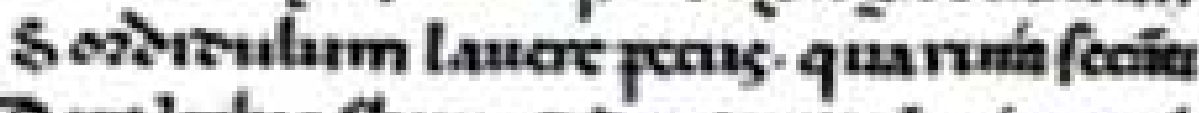

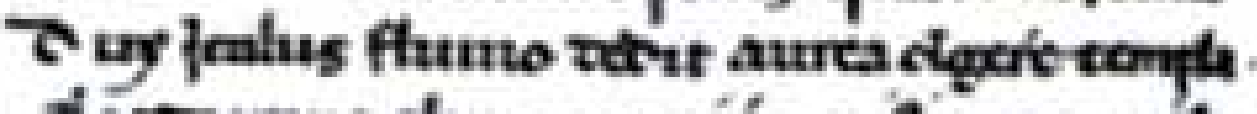

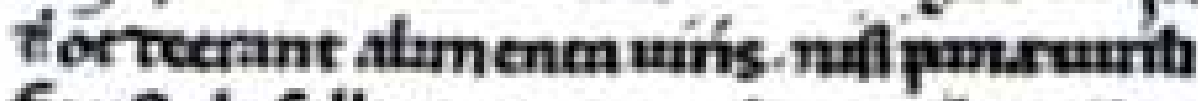
fauptuls folhatum eurni pre launfat:

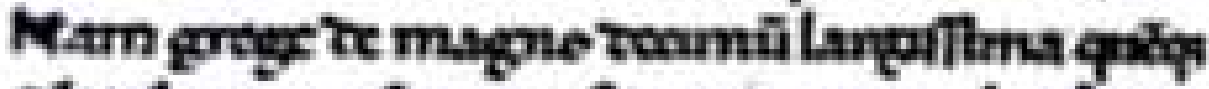

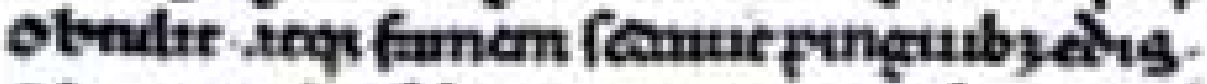

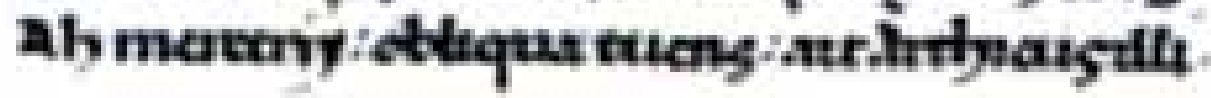

Fragmento de manuscrito de Francesco Petrarca ${ }^{22}$ 


\section{DOSSIÊ \\ Área Temática: Educação Visual, Linguagens Visuais e Arte}

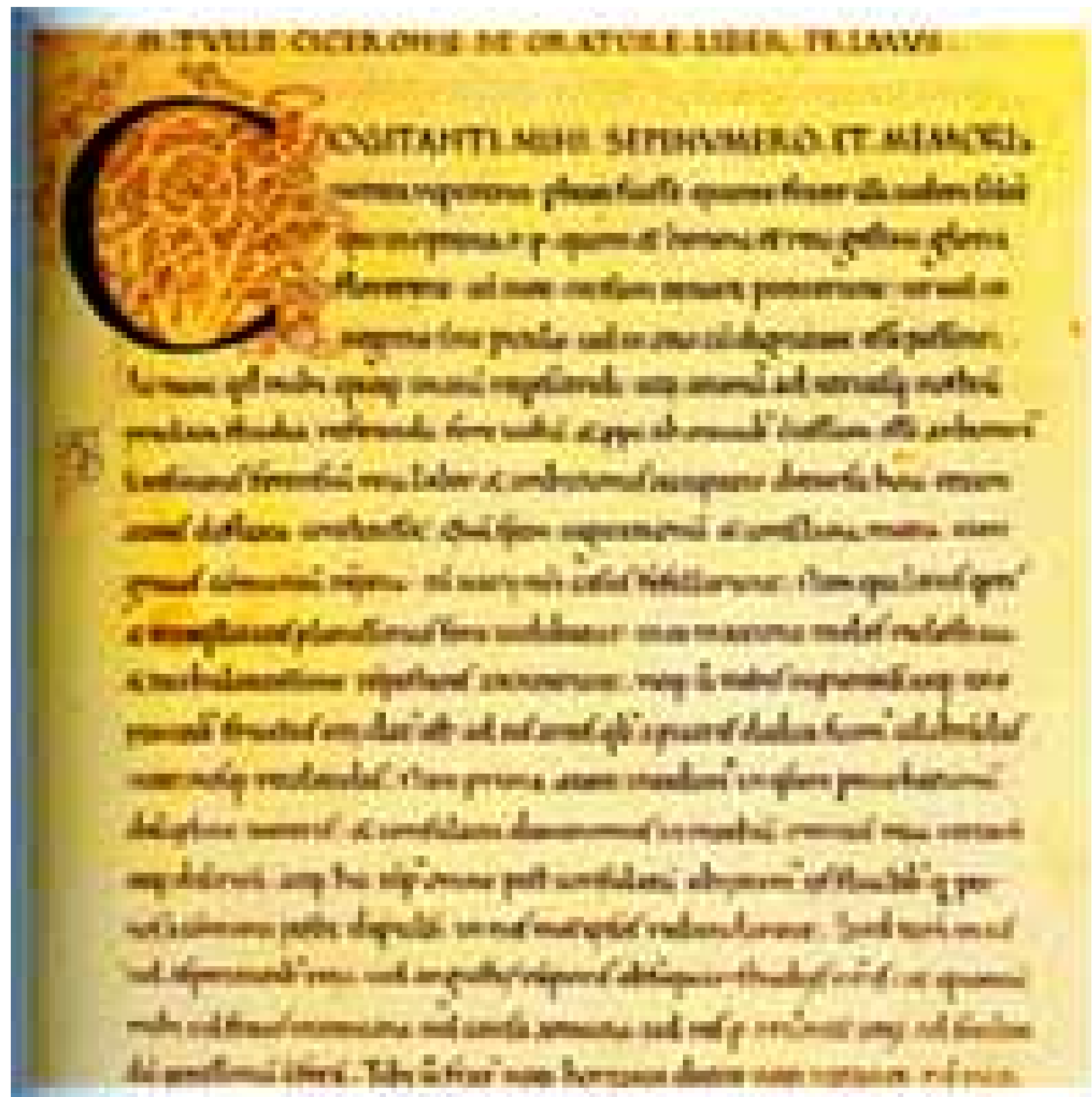

Fragmento de manuscrito de Poggio Bracciolini23 


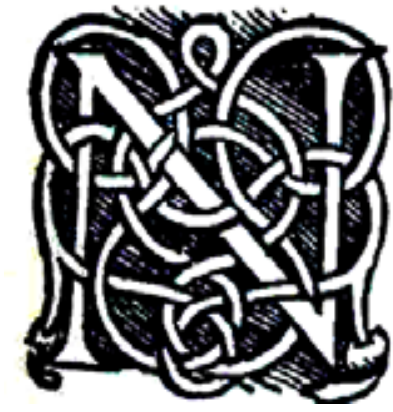

OS LIVROS IMPRESSOS ENTRE 1455 e 1500 - OS INCUNÁBULOS -, é comum vermos as letras góticas, utilizadas por Gutenberg e diversos outros tipógrafos. Lembram Idade Média e Alemanha. Não era uma regra, mas o mais comum pois na Alemanha os livros manuscritos, modelos para a composição dos livros impressos, tinham esse tipo de letra. Nesse mesmo período, paralelamente, outra letra - a Humanística, herdeira da Carolina - começou a ser empregada pela maioria dos impressores italianos. Regra, não havia, mas eles as copiavam dos livros manuscritos que na Itália foram influenciados pela cultura humanista associada ao Renascimento. Nesse movimento houve, já no século XIV, uma opção pela grafia contida nos códices produzidos no período carolíngio - que eram lidos, por exemplo, na Universidade de Bologna, onde Petrarca estudara direito. Parece que na elite cultural havia um preconceito ante as reminiscências ${ }^{24}$ da Idade Média - como as letras góticas - e assim seria natural que os humanistas tentassem apagar todo e qualquer vestígio daquele período, como a posição de Deus como centro das atenções, em detrimento do Homem.

"O homem do Renascimento, o humanista, estuda os textos antigos com um olhar novo, livre de qualquer dogma ou preconceito. A livre crítica da razão, a curiosidade e o gosto pelos valores humanos estão onipresentes.

Em um sentido mais amplo, o Humanismo é um sistema filosófico que coloca o homem no centro de um universo concebido à sua vontade e para a sua glória." 25

Na Universidade de Bologna também estudou Poggio Bracciolini, porém por apenas 2 anos, para se tornar notário em Florença. Os estudantes de direito ficavam oito anos na universidade.

Poggio foi copista, preceptor e empregado em contabilidade para custear seus estudos, antes de se tornar notário; nessa atividade, foi sócio 26 de Coluccio Salutati, chanceler de Florença. Todos eles, bibliófilos, foram marcantes para a difusão da letra Humanística que, minúscula, se tornaria mais tarde a preferida dos impressores italianos.

Era também chamada "antiqua", ou antiga, pois as góticas representavam a modernidade nesse período.

"Por outro lado, nossa fascinação pela força da arte não deve fazer-nos subestimar o poder do dinheiro e da política: não nos esqueçamos, por (C) ETD - Educação Temática Digital, Campinas, v.9, n.1, p.328-340, dez. 2007 - ISSN: 1676-2592. 


\section{Área Temática: Educação Visual, Linguagens Visuais e Arte}

exemplo, que em 1406 a Florença dos banqueiros e dos mercadores tomou a cidade de Pisa e comprou o porto de Livorno. Ademais, sem a profusão de encomendas realizadas pelos mecenas, a caligrafia não haveria conhecido tão importante desenvolvimento." 27

O livro que vemos e manuseamos hoje em dia tem mais de quinhentos e cinqüenta anos de memória. Bem mais! Apesar das constantes mudanças pelas quais ele passou, conserva, visualmente, características sensuais do livro do período renascentista e dos manuscritos que esse imitou até então. Houve muitos avanços mecânicos e eletrônicos na sua produção, além de outras no design, mas o objeto continua muito próximo daquele que escribas medievais e depois, editores renascentistas, nos legaram.

\section{BIBLIOGRAFIA}

AGAMBEN, Giorgio. Per una Lettura del Polifilo. IN: “Lettere Italiane”, Anno 34(4), $10-$ 12/ 1982, pp. 466-481.

ALMEIDA, Milton. O Teatro da Memória de Giulio Camillo. Cotia: Ateliê; Campinas: Unicamp, 2005

ARIANI, Marco/ GABRIELE, Mino. “Commento” IN: COLONNA, Francesco. Hypnerotomachia Poliphili - Tomos I e II. Milão: Gli Adelphi, 2006. BORGES, J orge Luis. Obras Completas - v. 1 e 2. São Paulo: Globo, 2000. DOTTI, Ugo. Vida de Petrarca. Trad. de André Nepomuceno. Campinas: Editora Unicamp, 2006.

GRIMAL, Pierre. Dicionário de Mitologia Grega e Romana. Trad. de Victor J abouille. RJ : Bertrand Brasil, 2005.

J AMESON, Fredric. As marcas do visível. RJ : Graal, 1995.

MEDIAVILLA, Claude. Caligrafia. Del signo caligráfico a la pintura abstrata. Trad. de Carlos García Aranda. Valência: Campgràfic, 2005. YATES, Frances. El Arte de la Memória.Trad. de Ignácio Gómez de Liaño. Madrid: Siruela, 2005 


\section{Área Temática: Educação Visual, Linguagens Visuais e Arte}

\section{NOTAS}

${ }^{1}$ Batalha de Amor em Sonho de Polifilo

${ }^{2}$ cf. YATES, 2005, p. 9.

${ }^{3}$ Protagonista do Hypnerotomachia Poliphili.

${ }^{4}$ Francesco Griffo da Bologna foi o gravador das letras utilizadas por Aldo Manuzio.

${ }^{5} \mathrm{cf}$. HOUAISS, 2001.

6 "Negro de fumo" - fuligem produzida pela combustão dos resíduos do pez(secreção resinosa do pinheiro e de várias árvores coníferas), do alcatrão e outras resinas. cf. MICHAELIS, 1998.

7 “Incunábulo" - começo, origem - livro impresso até o ano de 1500 - aceita-se 1520.

8 cf. J AMESON, 1995, p. 02.

${ }^{9}$ cf. BORGES, 2001, p. 665.

10 cf. BORGES, 2001, p. 664.

${ }^{11} \mathrm{cf}$. BORGES, 2001, p. 517.

12 cf. YATES, 2005, p. 09.

13 cf. ALMEIDA, 2005, p. 219.

14 cf. BORGES, 2001, p. 693.

${ }^{15}$ Cf. AGAMBEN, 1982, p. 470.

${ }^{16}$ Idem, 1982, p. 470.

${ }^{17}$ Cf. GRIMAL, 2005. “Ceres é o nome romano da deusa grega Deméter.” p. 84 Essa é a deusa maternal da Terra . . .divindade da terra cultivada, é fundamentalmente deusa do Trigo. . . . Os seus locais de eleição são as planícies de Elêusis". pp. 114.-115.

18 cf. DOTTI, 2006, p. 30.

19 cf. ARIANI-GABRIELE, 2006, p. 498 - TOMO II.

20 cf. DOTTI, 2006, p. 88. (Como se sabe, o Roman de la Rose, sobretudo em sua primeira parte, é a narrativa de um sonho. O autor se encontra diante do ingresso no maravilhoso jardim de Déduit (o Prazer), onde não se consegue fazer conhecer da senhora Ociosa. Aqui, entra numa dança, numa espécie de feliz dança de roda, com Déduit, o Amor, a Beleza, o Doce Olhar etc., e posteriormente, encantado por deliciosos gorjeios, visita um parque cheio das mais diversas árvores. Mas junto à fonte de Narciso, ferido pelas cinco flechas do Amor, da Beleza, da Simplicidade, da Cortesia, da Companhia e do Belo Semblante, enamora-se da Rosa. O Amor o ensina, então, as regras do bem amar e, entre outras coisas, o ensina a suportar as contrariedades e as tribulações. Essa obra erudita, totalmente fundada sobre a personificação e a alegoria, obteve na França enorme prestígio, pois que era uma espécie de código do amor cortês.)

21 Idem, 2006, p. 501 - TOMO II.

22 cf. MEDIAVILLA, 2005, p. 188.

23 Idem, 2005, p. 189

24 Idem, 2005, p. 191.

25 Idem, 2005, p. 187.

26 Idem, 2005, p.189.

27 Idem, 2005, p. 191.

UBIRAJARA ALENCAR RODRIGUES Pesquisador e mestrando do Laboratório de Estudos Audiovisuais OLHO, Faculdade de Educação, Universidade Estadual de Campinas E-mail: ubirajarale@gmail.com

Artigo recebido em: 11/12/2007

Artigo para publicação em: 20/12/2007

(C) ETD - Educação Temática Digital , Campinas, v.9, n.1, p.328-340, dez. 2007 - ISSN: 1676-2592. 